\title{
"A BENFAZEJA":
}

\section{O HOMEM EM BUSCA DE SI}

\author{
MARTA CAVALCANTE DE BARROS*
}

RESUMO: Apoiando-se nos mecanismos básicos de funcionamento do inconsciente - o deslocamento e a condensação -, a autora analisa o conto "A benfazeja", de Guimarães Rosa, observando como se tece sua intertextualidade com a peça Édipo Rei, de Sófocles.

PalaVRaS-CHAVE: Guimarães Rosa; Édipo Rei; Intertextualidade; Psicanálise

A alma cativa e obcecada

Enrola-se infinitamente numa espiral de desejo

\section{CARLOS DRUMMOND DE ANDRADE}

A produção de uma obra envolve não só o processo mesmo da escritura como também as experiências de leitura do autor, seu contexto histórico-social. Toda obra estabelece, na verdade, um inevitável diálogo com outras obras. Algumas vezes, esse diálogo torna-se tão intenso, que passa a haver uma "intertextualidade", ou seja, a criação de um discurso que reelabora um discurso alheio.

Guimarães Rosa - autor que sempre cultivou as formas clássicas dentro de um espírito de "imitação" - com seu conto, "A benfazeja", evidencia ecos da tragédia Édipo Rei. Isso não significa que houve apenas uma reescritura da tragédia; houve, sim, a criação de um texto que atualiza a problemática central da peça escrita por Sófocles: a busca da identidade, que se dá no enfrentamento pelo homem de seu próprio destino.

“A benfazeja" encontra-se no livro Primeiras Estórias, publicado em 1962.

* Mestranda em Teoria Literária e Literatura Por todos os contos desse livro, percebemos uma preocupação do autor em se Comparada na USP. 
(1) Esses mecanismos foram percebidos e estudados por Freud na análise de sonhos. Apesar de não envolver um trabalho consciente, $o$ sonho possui como "matéria-prima" os desejos inconscientes, os estímulos corporais vividos durante o sono, as imagens colhidas à experiência do dia anterior. Essa matériaprima é distorcida através também desses mecanismos e o sonho de que nos lembramos ao acordarmos - o conteúdo manifesto - torna quase ininteligível a essência do sonho - o conteúdo latente. Ver $\mathrm{S}$. FREUD, A Interpretação dos Sonhos, Rio de Janeiro, Imago, 1972 (Coleção Standard Brasileira, IV e V).

(2) A ambigüidade dessa afirmação revela o objeto mesmo da tragédia, exposto por Aristóteles na Poética: a tragédia procura imitar os homens "melhores do que eles ordinariamente são", ou seja, homens de caráter superior. ARISTÓTEles, Poética, trad. Eudoro de Souza, São Paulo, Nova Cultural, 1987 (Coleção Os Pensadores).

(3) Podemos associar as figuras de Mula-Marmela guiando o cego Retrupé às de Antígone e seu pai Édipo, que vagava pelo mundo, expiando sua culpa. situar na fissura entre o real e o surreal, entre o diurno e o noturno, entre o consciente e o inconsciente, buscando vislumbrar nas criaturas que habitam suas histórias sua gama de mistério, estranheza e perplexidade.

Nesse contexto de fissuras, a abordagem psicanalítica vem muito nos favorecer. $\mathrm{O}$ texto - compreendido enquanto tecido de significantes, como o espaço onde há o entrecruzamento de desejos, tanto do autor, como do leitor, do crítico e das personagens - passa a ser fruto de um trabalho de duas forças: a do consciente $\mathrm{e}$ a do inconsciente.

A criação de um texto envolve pulsões vitais profundas que afloram através dos mesmos mecanismos básicos utilizados pelo inconsciente para "driblar" as barreiras defensivas do ego: o deslocamento e a condensação. ${ }^{1}$ Portanto, a análise do texto não consiste apenas em sua leitura, mas na descoberta dos processos do seu trabalho de elaboração; é preciso focalizar seus trechos sintomáticos: deformações, ambigüidades, elisões, omissões, que podem constituir um modo valioso de acesso a esses impulsos inconscientes que participam de sua invenção.

No nosso caso, por ser o conto uma forma breve, que tende a economizar meios narrativos, condensando os recursos, contraindo os impulsos e tendo, portanto, como traços fundamentais de sua elaboração a contração e concentração, os procedimentos de deslocamento e condensação são fundamentais, ocupando um plano privilegiado na criação. O conto "A benfazeja", em seu diálogo com Édipo Rei, traz bastante evidenciados esses dois procedimentos de construção.

A estória é contada por um narrador pertencente à tradição oral que, dirigindo-se aos habitantes de um vilarejo, busca extrair alguma "verdade", alguma compreensão do fato "insólito" que ocorreu com três de seus habitantes: Mula-Marmela, Mumbungo e Retrupé, seres sem nenhuma importância: "A gente não revê os que não valem a pena", conhecidos somente através de seus apelidos.

No entanto, ao longo do texto, percebemos que esses "seres tão sem importância", que vivem de maneira diferente dos "honrados cidadãos" do lugarejo, têm seus pedidos de esmolas prontamente atendidos, pois são temidos e até respeitados. De acordo com o narrador: "Cada qual com sua baixeza; cada um com sua altura". No entanto, quem, de fato, está no baixo, e quem, no alto? ${ }^{2}$

Mula-Marmela, mulher "malandraja e malacafar", matou seu marido, Mumbungo, um homem hediondo, que constituía uma ameaça para todos os habitantes do vilarejo. Apesar de ter praticado um ato de bondade para com a cidade, Mula-Marmela viveu sempre no ostracismo, cuidando do cego Retrupé, filho de Mumbungo. Retrupé, tão irascível e orgulhoso quanto o pai, é tolhido pela cegueira, dependendo estranhamente dessa figura feminina, que caminha sempre a sua frente e que ele segue "caninamente". ${ }^{3} \mathrm{O}$ relacionamento entre ambos é o objeto de atenção do narrador, que tenta verificar o que precisamente 
se passa entre esses dois seres que mal se falam, aparentemente mal se suportam e estão sempre juntos.

Assim como a peça de Sófocles serviu a Freud para ilustrar sua teoria sobre o Complexo de Édipo, esse conto de Guimarães Rosa também mostraria alguns reflexos dessa teoria. Nele é perceptível a configuração do famoso triângulo amoroso que caracteriza a situação edipica: pai-mãe-filho. A presença do complexo colocará em jogo as relações existentes entre defesa, desejo, identificação, angústia, morte e sexualidade - ingredientes necessários a qualquer funcionamento psíquico e que verificaremos no texto.

Além da triangulação, a aproximação entre a tragédia de Sófocles e o conto de Guimarães Rosa se dá por muitos outros elementos, semelhantes e dessemelhantes. ${ }^{4}$ Em ambos os textos temos uma situação limite, um entrave do homem consigo mesmo, uma busca que se dá na direção do destino e da identidade.

O conto de Guimarães Rosa, exatamente por ser um conto e não uma peça teatral, restringe-se aos recursos da linguagem escrita. Dai termos um narrador, ao invés de um coro, que fala pelo e para o povo da cidade. Tecendo comentários sobre o plano das ações, sobre o comportamento das personagens e de seus próprios ouvintes, esse narrador externa uma preocupação ética, que busca extrair a verdade dos fatos. No entanto, essa verdade, no final do conto, não é atingida de todo; pois para Guimarães Rosa a Verdade terá um caráter paradoxal, que se manifesta na própria estrutura de ambigüidades e contradições do conto: o povo da cidade despreza Mula-Marmela e Retrupé, mas os teme e não tem como se livrar deles; ao mesmo tempo, tão poderosos e orgulhos, MulaMarmela e Retrupé vivem a esmolar. Retrupé odeia Mula-Marmela, é irascivel e temido; Mula-Marmela o traz "na coleira", mas é ela quem se abaixa humildemente para apanhar-lhe o chapéu, "nem preto nem branco", que não tira para ninguém. Ou seja, o que percebemos é um jogo entre a aparência e a essência, entre a Verdade e a Impressão, sendo que aquela vai se revelar, continuamente, relativa, de cada um. O narrador é aquele que indaga tudo, que busca o que há por debaixo das aparências, afinal é uma pessoa de fora: "Mas, eu, indaguei. Sou de fora". Desde o título do conto, esse narrador toma uma posição, considerando Mula-Marmela como a "benfazeja". É um narrador que expressa as opiniões do povo da cidade e as suas próprias, procurando mostrar também que nem sempre a Verdade pode ser atingida: "Se ninguém entende ninguém; e ninguém entenderá nada, jamais; esta é a prática da verdade". Relacionando sua figura com a peça de Sófocles, poderíamos dizer que ele condensa o coro e, de certo modo, a figura do cego Tirésias: aquele que sabe de tudo, que vê além.

As figuras do pai, mãe e filho, em Sófocles - Laio, Jocasta e Édipo -, estão no conto deslocadas e condensadas respectivamente nas figuras de Mumbungo, Mula-Marmela e Retrupé.

Retrupé, o filho, traz, como Édipo, a palavra "pé" embutida em seu nome/ apelido; e mais, um "pé" que tem o andar defeituoso, atrapalhado: "retru". O
(4) É interessante notar que a intertextualidade constitui-se não apenas de acordos, mas também de desacordos, de constantes transgressões de um texto para outro. 
gênio de Retrupé é semelhante ao de Édipo: ambos são irascíveis e orgulhosos, além de não conseguirem ouvir o outro. Um dos motivos pelo qual Édipo atinge seu destino trágico é sua atitude de jamais ouvir os outros, prosseguindo sempre seu próprio caminho e, quando ouve, perceber apenas o que lhe é conveniente. Retrupé é assim caracterizado pelo narrador: "se alguém falasse, ou risse, ele parava, esperava o silêncio. Escutava muito ao redor de si. Mas nunca ouvia tudo, não sabia, nem podia" (grifo meu).

Tanto Édipo quanto Retrupé são marcados pelo "Poder”. Aquele era Rei de Tebas, e este traz essa marca implícita, "mais seria como se percebessem nele, de obscuro, um mando de alma, qualidade de poder". E, finalmente, Retrupé é cego, ou melhor cegou-se. Mas, se em Édipo Rei esse ato fica claro, no conto de Guimarães Rosa não; a linguagem é bastante ambígua: “ainda não estava cegado naqueles tempos [...]. Só aí, se deu que, em algum comum dia, o Retrupé cegou, de ambos aqueles olhos" (grifos meus).

$\mathrm{O}$ assassinato do pai, Mumbungo, não é realizado pelo filho, mas por Mula-Marmela, a mãe. Não foi este um ato que trouxe a "peste" para a cidade, mas um ato que livrou a cidade de uma "peste", afinal Mumbungo era um indivíduo que oferecia "perigo e castigo" para os habitantes do lugarejo. Talvez por isso, percebemos em sua figura a condensação da Esfinge, o monstro que amaldiçoava Tebas antes da chegada de Édipo. Mumbungo foi assassinado por Mula-Marmela, que não era a mãe natural de Retrupé, pois ela nunca havia parido. Assim como Édipo e Retrupé, Mula-Marmela apresentava dificuldades no andar: "andava meio agachando, joelhos para adiante". Dentro da tradição literária - sobretudo no mundo grego - é comum associar-se a dificuldade de andar a uma conotação moral, implicando uma dificuldade de manter-se no caminho "correto". De fato, Mula-Marmela é caracterizada pelo narrador como uma pessoa "suja de si", maldita; no entanto, sendo uma "mula" e andando meio agachada, sua dificuldade de andar deve-se mais ao fato de carregar um grande fardo nas costas, apesar de este não ser visível.

Mula-Marmela merece bastante atenção por parte do narrador, que procura compreender sua personalidade dual, desvelando suas camadas: "nem fosse reles, feiosa, isto vocês poderiam notar se capazes de descobrir-lhes as feições sob o sórdido desarrumo do sarro e crasso; e desfixar-lhe os rugamentos, que não de idade, senão de crispa expressão". Na verdade, Mula-Marmela é a "maldita" para o povo da cidade e, para o narrador, ela é uma espécie de "bode expiatório". Seus atos possuem sempre dupla significação: negativa, quando desvelada, pública, para o povo da cidade; e positiva, quando revelada pelo narrador. E novamente o narrador aproxima a figura dessa mulher à do decifrador de enigmas de Sófocles: "Compensem-lhe as palavras parcas, os gestos, os atos e terás que ela se desvendava ladina, atilada em exacerbo" (grifo meu). Apesar da astúcia e da esperteza, Mula-Marmela encarna uma figura feminina, conservando-se no âmbito dos sentimentos e do carinho: "Repararam como olha para as casas com os olhos simples, livres do amaldiçoamento do pedidor? 
E não põe no olhar das crianças o soturno do cativeiro que destinaria aos adultos. Ela olha para tudo com singular admiração [...]. A Marmela, pobre mulher, que sentia mais que todos, talvez, e sem o saber, sentia por todos". Essa afirmação evoca diretamente as palavras de Édipo na peça de Sófocles: "Não ignoro que todos sofreis. Em vossa dor, porém, nenhum de vós sofre tanto quanto eu. Cada um sofre o quinhão de um só e mais nada, enquanto meu coração geme por todo o povo, por ti e por mim juntamente."s Essas palavras farão um sentimento desvelador no final do conto, quando Mula-Marmela novamente vai agir em favor da cidade.

O relacionamento de Mula-Marmela e Retrupé, tão estranho, mescla de ódio e amor, incompreensível aos demais, é igualmente objeto de atenção para o narrador: "Desciam a rua, dobraram o beco, acompanharam-se por lá, os dois, em sobrossoso séqüito. Rezam-se ódio. Lé e cré, pelas ora voltas, que qual, que tal, loba e cão. Como era que ficavam nesse acordo de incomunhão, malquerentes, parando entre eles um frio figadal?" Para explicar essa relação o narrador vai trabalhar com dois pressupostos: o primeiro, Retrupé era filho do finado marido de Mula-Marmela e ela se vê na obrigação de cuidar dele, e o segundo, Retrupé representa para Mula-Marmela o filho que ela nunca teve e talvez por isso queria-lhe bem, apesar dos gestos e palavras parcas: "Não, não há ódio; engano. Ela não. Ela cuida dele. Guia-o, trata-o - como a um mais infeliz, mais feroz, mais fraco". Este segundo pressuposto prevalecerá e será explorado por todo o conto até a revelação final.

Mas, e Retrupé? Apesar de todo o seu ódio que dirigia aos outros, sua vontade de matar e ferir - atitude oposta à de Mula-Marmela - ele a temia: "Temia-a, a ela, à mulher que o guiava. Mula-Marmela chamava-o, com simples sílaba, entre os dentes, quase esguichado um "ei" ou "hã" - e o Retrupé se movia de lá, agora apalpante, pisando com ajuda; balançava o facão, a bainha presa a um barbante, na cintura. Sei que ele, leve, breve, se sacudira".

Como conciliar o medo e ódio de Retrupé e o Complexo de Édipo, que a princípio implica no amor pela mãe? O medo pode ser, muitas vezes, o substituto de um desejo sexual reprimido, já que a recordação poderia causar uma idéia aterradora do que significa obter a satisfação sexual - no caso, possuir aquela que em sua realidade psíquica ocupa o lugar da mãe. No texto, essa satisfação é obtida através de um deslocamento: Retrupé não possui Mula-Marmela, mas é ela quem o guia para obter essa satisfação com outras mulheres: "ela mesma o conduz, paciente, às mulheres, e espera-o cá fora, zela para que não o maltratem".

Outro traço importante na caracterização de Retrupé, como já ressaltamos, é o orgulho, a arrogância e a irascibilidade: "Notem que o cego Retrupé mantém sempre muito levantada a cabeça por inexplicável orgulho". Essa falta de respeito pelo outro, a posse do facão que carrega ostensivamente na cintura, $o$ orgulho "inexplicável", simbolizado pelo chapéu - o mais alto ponto do corpo - que ele não tira para ninguém, são índices da defesa de Retrupé, que parece
(5) In SÓFOCles, Teatro Grego, trad. Jaime Bruna, São Paulo, Cultrix, 1989. 
(6) Lembremo-nos do comentário de Vernant sobre a personagem Édipo de Sófocles: "Mas o próprio peso dessa falta que deve assumir sem tê-la cometido intencionalmente, a dureza de um castigo que suporta serenamente sem tê-lo merecido, o elevam acima da condição humana, ao mesmio tempo que o separam da sociedade dos homens". Em J.P. VERNANT, Mito $e$ Tragédia na Grécia Antiga, São Paulo, Duas Cidades, 1977, p. 56. imerso em si mesmo, envolto por uma espécie de narcisismo primário, infantil. No entanto, verificamos o quanto suas defesas são frágeis, pois o facão é amarrado à bainha, que é presa por um barbante, um simples e frágil barbante.

Ligados ao Complexo de Édipo e ao narcisismo estão o Amor e o Ódio. Freud notou que "Amor" e "Ódio" devem ser reservados para a relação do ego com os objetos totais. Num primeiro momento, o ego coincide com o prazer e o mundo externo com o indiferente e o desprazeroso: é o momento narcisista. Daí, para restabelecer a satisfação narcisista, o ego introjeta os objetos gratificantes do mundo exterior e projeta para este tudo aquilo que, nele próprio, é fonte de desprazer.

No momento em que o narcisismo dito "primário" é invadido pelo objeto, emerge a antítese do amor: a oposição amor/ódio. O ódio pode ser compreendido como uma forma de lidar com os objetos externos que representam uma fonte indesejada de desprazer. Geralmente, nessa situação se estabelece uma forte repulsão frente ao objeto.

Inserindo essas colocações no Complexo de Édipo, verificamos que a superação desse complexo envolve o temor narcísico - o temor pela castração, pela mutilação, muitas vezes simbolizada pela perda da visão, dos olhos - e o posterior reconhecimento do outro.

O que parece ter havido com Retrupé é exatamente um retorno à fase narcísica por temor à realidade. Sua agressividade tornou-se um mecanismo de restauração narcísica. Além disso, cria defesas para a proteção de seu ego. A cegueira, ao mesmo tempo em que representa o temor pela castração, está associada ao isolamento, que consiste na destruição da conexão entre as idéias e o seu significado emocional: "Para ele, graças à cegueira, este nosso mundo já é algum além." De qualquer maneira, as defesas são fracas; Mula-Marmela é uma constante que ele não consegue evitar, não há como não a encarar, apesar da cegueira: "mesmo um que não vê, sabe que precisa de apartar a cabeça: ele faz isso para não encarar com a mulher odiosa".

Com o passar do tempo, algo entre eles vai, aos poucos, se modificando: "E, no entanto, ela cada dia para com ele mais se abranda, apiedada de seu desvalor. Mas ele não crê, não pode saber, não confia dela, nem da gente. [...] Ele sussurra disfarçada e impessoalmente seus pedidos de perdão". Esse abrandamento nas barreiras da defesa vai acarretar sua queda total: "Conta-seme que ele quis matá-la. Em hora em que seu medo se derramou maior, saberse-á lá por quê? Tido que já se estava maltreito, quando adoeceu, mal, de febre acesa. Sentara-se à beira da rua, para arquejar. De repente, levantou-se, sem bordão, estorvinhado, gritou, bramou: exaltado como um cão que é acordado de repente. Sacou o facão, tacava-o, avançava às doidas, às mesmo cegas, tentando golpeá-la, em seu desatinado furor. [...] Mas, aos poucos, acreditou que o facão não a encontraria nunca, sentiu-se desamparado demais e sozinho. Temeu, de todo em pé. $O$ facão lhe caiu da mão. Seu medo não tinha olhos para encher." (grifo nosso). Esse momento é, analogamente à tragédia Édipo Rei, 
um misto de peripécia e anagnorisis, isto é, reviravolta da ação e reconhecimento da própria identidade e daquele com quem se relaciona. Apesar das lacunas constantes no texto, algo se passou com Retrupé e ele tenta matar aquela que não conseguiu eliminar em sua realidade psíquica. Saca seu facão - índice maior de seu narcisismo - e tenta, com ele, eliminar o objeto externo que lhe causa tanto terror. Ao se ver impossibilitado de realizar o ato, dá-se a reviravolta: Retrupé vê Mula-Marmela, não mais com ódio, mas como o Outro: “Mãe... Mamãe... minha mãe!"?

Esse reconhecimento do Outro é o reconhecimento de si mesmo como sujeito, mas que não é aceito por Retrupé, pois esse sujeito, pela existência do Outro, revela-se cindido, partido; um sujeito habitado pelo Desejo, que sempre é o desejo de abolir a divisão, que o assinala como o horizonte do impossível: $o$ objeto já estava perdido. E também a própria realidade lhe proíbe o acesso ao objeto por excelência, o primeiro e o mais fundamental de todos: a mãe. Sabendo impossível a coincidência com o objeto de seu desejo, Retrupé fantasia a dependência infantil da mãe através de sua cegueira. No entanto, ainda não aceitando a divisão e diante de uma realidade inexorável, que se apresenta através do reconhecimento de Mula-Marmela como mãe, nada lhe resta além da morte, promessa de unidade, que lhe chega cheia de angústia e sufocações... Novamente temos aqui uma inversão. Em Édipo Rei o reconhecimento da mãe leva à cegueira; no conto de Guimarães Rosa, Retrupé já está cego - maneira de manter-se refugiado, seguro do mundo exterior. É o reconhecimento de MulaMarmela como mãe que o leva a um estado análogo à cegueira de Édipo: a morte. As duas passagens são marcadas por sentimentos de angústia e profunda dor. O corte foi feito.

Dessa maneira, mais uma vez, a realidade cedeu lugar à ilusão. E, lembrando-nos de Freud, podemos afirmar que a ilusão em si não é um erro; mas é sim a realização imaginária de um desejo, ou melhor, do Desejo, da ânsia de coincidir, da sede da identidade. Ora, talvez o que Retrupé não tenha percebido é que o mesmo só se expressa no Outro e que o Outro é o retorno do Mesmo sobre sua própria diferença. A ilusão aparece assim como negação da realidade, constituída por divisões insuperáveis, frente às quais a angústia da primeira separação - o nascimento - se repete e prolifera, exigindo a repressão. Mas a repressão não elimina o desejo de identidade: ela o toma a seu serviço, transformando-o e fazendo surgir o sentimento de culpa por desejar e persistir no desejo.

Nessa luta, nessa busca, Retrupé perdeu-se. Jamais aceitando a divisão, não reconhecendo-se como sujeito, negou-se.

E Mula-Marmela? "E ela ia se indo, amargã, sem ter de se despedir de ninguém, tropeçante e cansada. [...] o que figurava a expedição do bode - seu expiar". Novamente o deslocamento da figura de Édipo, condensada na mãe: vagando pelo mundo, Mula-Marmela tenta expiar seu fardo, em sua jornada solitária. Ela é, sem dúvida, a própria figura do bode expiatório, aquela que
(7) Ressalto também o caráter sexual desse ato de Retrupé que, com seu facão, tenta atingir, perfurar, penetrar naquela que reconhecerá como mãe. 
livra a cidade não apenas do mal, mas do "miasma". Atitude que fica clara com o seu ato, estranho ato, ao partir: "Ela avistou aquele um cachorro morto, abandonado e meio já podre, na ponta-da-rua, e pegou-o às costas, o foi levando -: se para livrar o logradouro e lugar de sua pestilência perigosa, se para piedade de dar-lhe cova em terra, se para com ele ter com quem ou quê se abraçar, na hora de sua grande morte solitária?" Ou se para tudo isso conjuntamente.

ABSTRACT: Starting from the basic mechanisms of the unconscious - displacement and condensation - the author analyses Guimaräes Rosa's short story "A benfazeja" lighlighting the intertextual relationship with Sophocles' play Oedipus Rex.

KEYwordS: Guimarães Rosa; Oedipus Rex; Intertextuality; Psichoanalysis

Texto elaborado para a disciplina Aspectos da abordagem psicanalítica do texto literário, ministrada pela Profa. Dra. Cleusa Rios Pinheiro Passos, no 2ºmestre de 1993. 